\title{
DISPOSABLE MENSTRUAL PRODUCTS AS LAW'S OBJECTS
}

\section{BETH GOLDBLATT \& LINDA STEELE*}

\section{INTRODUCTION}

During the past few years, scholars and activists have increasingly engaged with law as a means to challenge stigma, silence, and disadvantages associated with menstruation. Menstrual items (predominantly in the form of disposable menstrual products) ${ }^{1}$ are becoming increasingly prominent in this "legal turn." ${ }^{2}$ There have been legislative reforms to provide access to free menstrual items, litigation and legislative reforms to remove taxes on menstrual products, legislative reforms on product safety and environmental sustainability of menstrual items, and water and sanitation hygiene ('WASH') policies and guidelines in the context of international development interventions that focus on access to menstrual items. ${ }^{3}$

As regulation of disposable menstrual products assumes greater prominence in legal doctrine, feminist legal scholars are increasingly evaluating the impacts of such laws on menstruators, including in the context of diverse experiences of menstruation and

\footnotetext{
${ }^{*}$ Faculty of Law, University of Technology Sydney, Australia. Thank you to Jessie Hohmann for her feedback on an earlier draft.

${ }^{1}$ Conventionally in a contemporary western context, menstrual items might be thought of as menstrual/period/feminine hygiene products, and specifically disposable pads and tampons that are consumed in the market. Yet, the concept of 'menstrual item' itself is not fixed. New menstrual products such as cups, period underwear, and more sustainable disposables are emerging in the market. See, Maria Carmen Punzi and Mirjam Werner, Challenging the Menstruation Taboo One Sale at a Time: The Role of Social Entrepreneurs in the Period Revolution, in The Palgrave Handbook of Critical Menstruation Studies 833 (Chris Bobel et al. eds., Palgrave Macmillan 2020). However, culturally and historically there is a wider variety of material items that are used in relation to menstrual blood and menstruation more broadly, including handmade, home-grown and reusable items. In this Essay we focus on one specific category of menstrual item - disposable pads and tampons ('disposable menstrual products') which still dominate law reform responses to period poverty.

${ }^{2}$ Linda Steele \& Beth Goldblatt, Engaging with Law's Menstrual Moment, AusTL. Feminist L.J., 1, 1-31 (2020).

${ }^{3}$ See id., for a discussion of international legal responses to menstrual inequality.
} 
menstrual injustice. ${ }^{4}$ But what can disposable menstrual products themselves tell us of law? In this Essay we take an object-informed approach to law in the specific context of disposable menstrual products. What insights about law might these objects provide, and how do these insights deepen our understanding of law's relationship to menstruation, menstruators, and the worlds in which menstruators are situated? What can we appreciate about law's role in defining, as well as recognizing and responding to, the diversity of experiences related to menstruation? How do menstrual items nuance our understanding of agency in relation to menstrual injustice? And what do these objects tell us about the limits and challenges of using law to achieve justice in relation to the embodied experiences of people who menstruate?

Part II introduces some key contributions to feminist legal thinking on materiality and objects, which informs our analysis of disposable menstrual products as law's objects. Part III introduces some of the critical threads in scholarship on disposable menstrual products, including how they relate to diversity and materiality of experiences of menstruation. Then, we turn in Part IV to explore what disposable menstrual products tell us about law's role in menstruation, using the recent laws introduced in Scotland as a case study.

\section{Foregrounding the Object in Feminist Legal Analysis: Theories on Materiality and Law}

Critical legal scholars, and amongst them feminist legal theorists, have engaged in rich explorations of how law is made and how it contributes to making our world. Recent scholarship examines how objects, technologies, and non-human agents inform our understanding of law rather than assuming that law is delinked from the material world and shaped by concepts and discourse alone. ${ }^{5}$ By foregrounding the object and the work it does - in this case, menstrual products - we can gain insight into how law deals with demands for social change and, in so doing, addresses some injustices but maintains others.

The material (re)turn in feminist theory, a critical response to post-modernism, requires a focus on the embodied human within the physical world and the everyday

\footnotetext{
${ }^{4}$ For example, Beth Goldblatt \& Linda Steele, Bloody Unfair: Inequality Related to Menstruation Considering the Role of Discrimination Law 41(3) SyDNEY L. REv. 293 (2019), where we question whether tax law reform will address the needs of groups such as menstruators with disabilities or trans menstruators.

${ }^{5}$ Emily Grabham, Brewing Legal Times: Things, Form, and the Enactment of Law 34 (2016).
} 
situation of people with material needs. ${ }^{6} \mathrm{~A}$ focus on the material is also about economics and the capacity of law to play a (re)distributive role in response to poverty and need. ${ }^{7}$ While 'old' materialism in the historical materialist tradition still has much to offer, "new materialism represents a genuine effort to give matter its due and to theorize the entanglement of mind and body, nature and culture, human and non-human forms of agency." ${ }^{8}$ Conaghan urges an attentiveness to the material as well as to the discursive in understanding how law might be engaged by feminists to generate change. ${ }^{9}$

Davies argues that new materialism and its adoption by some feminists is well aligned with another trend in theory — posthumanism. This approach challenges the human-centeredness of theory and the Western individualized conception of the self. ${ }^{10}$ Moving away from the Western tradition requires rethinking the human relationship to the earth, an urgent need within the era of the Anthropocene. ${ }^{11}$ While feminist theory has understood law as situated within the 'social,' this idea of society cannot be understood as purely human but must be seen ecologically as involving integration of human and non-human life and matter. ${ }^{12}$

Writing in the context of international law and bringing together many of the theoretical threads introduced above, Hohmann argues for the analytical value of "fixing the object as our frame of reference" in order to open up new ways of thinking about the law. ${ }^{13}$ Centering objects illuminates more intimate and local spaces of analysis ${ }^{14}$ and

\footnotetext{
${ }^{6}$ Joanne Conaghan, Feminism, Law and Materialism: Reclaiming the 'Tainted' Realm, in The AsHgate Research Companion to Feminist Legal Theory 31 (Margaret Davies and Vanessa E Munro eds., 2013).

${ }^{7} I d$. at 35 .

${ }^{8} I d$. at 41 .

${ }^{9} I d$. at 47 .

${ }^{10}$ Margaret Davies, Beyond Identity: In Theory, in Feminism, Postfeminism, And Legal Theory

BEYOND THE GENDERED SubJECT 151, 159 (Dorota Gozdecka and Anne Macduff eds., Routledge 2019).

${ }^{11} I d$. at 160.

${ }^{12} I d$.

${ }^{13}$ Jessie Hohmann, The Lives of Objects, in InTERnAtional Law's OBJects 30, 32 (Jessie Hohmann and Daniel Joyce eds., Oxford University Press, 2018).

${ }^{14} I d$.
} 
makes us think more concretely and materially about the operation of law. ${ }^{15}$ Objects can deepen our understanding of law's role in colonialism because "material objects have played a prominent role in the construction of colonial and imperial orders, ... and in the contestation of colonial rule." ${ }^{16}$ Lastly, objects help us to understand the "vitality, and ... . continued relevance, of . . . law as something itself acting in and on the world"17 and open the possibility that humans are not "the sole agents at work in the world," but rather one aspect of a broader and complex network of vitality, which includes non-human animals, the environment, micro-organisms, etc. ${ }^{18}$

We draw on aspects of these analytical developments in feminist legal theory to provide an object-informed frame within which to think through efforts by the movement for menstrual justice to engage law. A focus on period products as the material objects that law invokes and through which it operates offers a lens into the function of law, its impacts, and implications for future struggle.

\section{Critical Responses to Disposable Menstrual Objects}

Menstrual items are a central critical concern in menstrual scholarship. Some scholars have highlighted the significance of menstrual products to menstrual justice. McCarthy and Lahiri-Dutt point to the subversive role of period products in disrupting stigma, such as in the case of Indian activists "challenging public stigma around menstruation by brandishing bloody pads." ${ }^{.19}$ Others have highlighted the positive shift from disposable menstrual products towards reusable and sustainable products, as well as advances in disposable menstrual product safety. ${ }^{20}$ Still others highlight the importance of period products to enabling menstruators - especially those from marginalized backgrounds - to access education and the economy, broader physical safety, and

${ }^{15} I d$.

${ }^{16}$ Id. at 373 .

${ }^{17} I d$. at 33 .

${ }^{18} I d$. at 42 .

${ }^{19}$ Annie McCarthy \& Kuntala Lahiri-Dutt, Bleeding in Public? Rethinking Narratives of Menstrual Management from Delhi's Slums, in The Palgrave Handbook of Critical Menstruation Studies 15, 17 (Chris Bobel et al. eds., 2020).

${ }^{20}$ Nancy K Reaume, Toxic Shock Syndrome and Tampons: The Birth of a Movement and a Research: 'Vagenda' in The Palgrave Handbook of Critical Menstruation Studies 687 (Chris Bobel et al. eds., 2020). 
emotional and economic wellbeing. ${ }^{21}$ The growing openness about blood in menstrual product advertising is considered an advance in terms of visibility and confronting menstrual stigma. ${ }^{22}$

However, critical menstruation scholarship draws attention to the tensions, complexities, and contradictions apposite to disposable menstrual products, notably in relation to a broader structural context. Bobel and Fahs argue that: "hypervisibility of menstrual products (often white, clean, and increasingly, environmentally-friendly) has ultimately (and ironically) moved menstruation back into hiding and, more importantly, largely failed to examine the bedrock of menstrual stigma." ${ }^{23}$ Some argue that merely providing menstrual products does not address the structural inequalities experienced by marginalized menstruators ${ }^{24}$ while others argue that products as commodities within the market reinforce the idea that consumption is the solution to social problems. ${ }^{25}$ The centrality of capitalism to menstrual products is further complicated by the framing of products in terms of empowerment. ${ }^{26}$ Some highlight the history of menstrual products as related to sexism and racism - most evident in their name 'hygiene products' - explicitly connecting to histories of eugenics. ${ }^{27}$ Others point to the Western approach to hygiene and notions of cleanliness that privileges management and concealment over other knowledge and traditions of bodily care. ${ }^{28}$

\footnotetext{
${ }^{21}$ Jennifer Weiss-Wolf, Periods Gone Public: Taking a Stand for Menstrual Equity (2017).

${ }^{22}$ Punzi \& Werner, supra note 1, at n.2.

${ }^{23}$ Chris Bobel \& Breanne Fahs, From Private to Public: Shifting from the Politics of Bloodless Respectability to Radical Menstrual Embodiment, 45(4) Signs 955 (2020).
}

${ }^{24}$ See, e.g., Shailini Vora, The Realities of Period Poverty: How Homelessness Shapes Women's Lived Experiences of Menstruation, in The Palgrave Handbook of Critical Menstruation Studies 31, 42 (Chris Bobel et al. eds., 2020).

${ }^{25}$ Bobel \& Fahs, supra note 23, at 19.

${ }^{26}$ Bridget Crawford, Against Menstrual Capitalism, Feminist Law Professors (June 25, 2018), https://www.feministlawprofessors.com/2018/06/against-menstrual-capitalism/ [https://perma.cc/767B-8N3G]; Ela Przybylo \& Breanne Fahs, Empowered Bleeders and Cranky Menstruators: Menstrual Positivity and the "Liberated" Era of New Menstrual Product Advertisements, in The Palgrave Handbook of Critical Menstruation Studies 375 (Chris Bobel et al. eds., 2020).

${ }^{27}$ Steele \& Goldblatt, supra note 2, at n.1.

${ }^{28}$ Kuntala Lahiri-Dutt, Medicalising Menstruation: A Feminist Critique of the Political Economy of Menstrual Hygiene Management in South Asia, 22(8) Gender, Place \& Culture 1158 (2015). 
The use of disposable menstrual products as a central component of WASH agendas has been criticized as contributing to Global North/South power dynamics that abject Black and Brown women, constituting "the proper human as the clean, contained, and implicitly White body." ${ }^{29}$ At the same time, poverty is a real obstacle to meeting societal expectations of menstrual 'management', and demanding state resources-including products - to address the multi-dimensional inequalities facing menstruators can be an important strategic goal. Bobel and Winkler note that the decision by those in positions of privilege to deny products to women in the Global South that are available to women in the Global North raises complex questions. ${ }^{30}$

These critiques raise important considerations when reflecting on law reforms that center on period products. Yet, they do not specifically consider what law is doing in relation to period products, what period products do to law, and the relationship between law and period products in shaping understandings and practices of justice.

\section{A Critical Examination of Period Products as Law's Objects: The Scottish Case}

In November 2020 Scotland's Parliament approved the Period Products (Free Provision) (Scotland) Bill. The legislation, which came into effect on January 12, 2021, requires the government to provide free products to all who need them and requires their provision in educational settings. ${ }^{31}$ Advocacy around the Bill focused on the notion of period poverty ${ }^{32}$ however, insofar as the Bill requires universal provision, it contains notions of equality and rights for all menstruators. The Bill is interesting in a number of respects. For instance, in requiring the state to ensure that menstruators have access to products, it de-privatizes the issue of menstruation, making it the subject of public provision. The very existence of the legislation is an acknowledgement that menstruation is a public, visible issue. It also offers different kinds of products in an important

\footnotetext{
${ }^{29}$ Shenila Khoja-Moolji, Death by Benevolence: Third World Girls and the Contemporary Politics of Humanitarianism, 21(1) FEMINIST THEORY 65, 75 (2019).

${ }^{30}$ Chris Bobel \& Inga Winkler, "Bizarre and Backward:" Saviorism and Modernity in Representations of Menstrual Beliefs and Practices in the Popular Media, Feminist Formations (forthcoming).

${ }^{31}$ Period Products (Free Provision) (Scotland) Act 2021, § 1-2.

${ }^{32}$ Ailsa Burn-Murdoch and Joel McTaggart, Period Products (Free Provision) (Scotland) Bill, SPICe Briefing, The Scottish Parliament, 30 October 2019, 4.
} 
acknowledgement of the user's choice. ${ }^{33}$ In treating period products in the same way as other items found in Western public bathrooms, such as toilet paper and soap, the Bill addresses inequalities inherent in the pre-existing system of provision. The legislation also emphasizes the dignity of people obtaining products. ${ }^{34}$

At the same time, however, the focus on products as a response to period poverty means that the government can claim to have addressed the gender disadvantage facing menstruators without meaningfully confronting the structural inequalities underpinning it. In this respect, period products (viewed through an object-focused approach) are a vehicle through which law is used to make society or the government appear benevolent and just. However, the structural causes of menstruators' poverty embedded in the economic system are thus overlooked. Provision of products is a limited solution to overall poverty, including its gendered dimensions.

The legislation and its supporters use products as a means of addressing stigma by acknowledging past discrimination. However, the products themselves are not enough to tackle the shame and disgust attached to menstruation. The product as object of the law stands in for more substantive change that remains elusive. Yet, the products themselves, as material objects brought into reality through law, may impact lived experiences of stigma, silence, and shame and related attitudes. The interaction and interrelation between law as a provider of products, the products themselves, and their users, observers, deliverers, etc., may in fact alter the lived experience of menstruation in unanticipated ways. For example, menstruators seeing products in public facilities may start to question prior assumptions about the individual's responsibility for menstruation. Helping themselves to products in shared spaces may counter some of the shame associated with products and practices of hiding these products. School and local government administrators tasked with ensuring the provision of products may become more conscious of menstruators' needs.

The Scottish legislation defines 'period products' as "manufactured articles the purpose of which is to absorb or collect menstrual flow" 35 and include "tampons, sanitary towels and articles which are reusable." 36 The inclusion of reusable items is a positive acknowledgment of the need to address sustainability; but, the legislation does not

\footnotetext{
${ }^{33}$ Period Products (Free Provision) (Scotland) Act 2021, §6A(b) (Scot.).

${ }^{34} I d$. at $\S 6 \mathrm{~A}(\mathrm{a})(\mathrm{ii})$.

${ }^{35} I d$. at $\S 9 \mathrm{~A}(\mathrm{a})$.

${ }^{36} \mathrm{Id}$. at $\S 9 \mathrm{~A}(\mathrm{~b})$.
} 
include measures to educate users about the newer reusable options, nor does it require that products be environmentally safe. The objects that are given life through this law may well contribute to environmental harm, whereas the law could have been an opportunity to promote justice for menstruators in a context that decenters the human in the living world. The focus on manufactured products reinforces the message that menstruators require commodities of the market to address their needs; however, the socialization and demarketization of products by making them free simultaneously challenges this message.

There is no mention of culturally appropriate products in the legislation, which implies that all menstruators have similar needs and expectations. This points to the role of law in shaping social behaviors around products viewed through a western, monocultural lens. Yet, the legislation is more inclusive in other ways: it uses gender neutral terms to refer to persons in need of period products, thus acknowledging that menstruators may include transgender people. It also provides an exemption for the costs of product delivery where "the person could not reasonably obtain products in accordance with the arrangements in any other way." ${ }^{37}$ This appears to recognize the needs of people with disabilities and illnesses, people in rural or remote areas, and disadvantaged menstruators with financial barriers to access. Additionally, the legislation requires consultation by authorities tasked with providing products with product users. ${ }^{38}$ This is an important acknowledgment of the need for appropriate, local responses and may offer opportunities for affected people and groups - such as racial minorities or people with disabilities - to contribute their knowledge and views on acceptable products and their provision. The legislation's references to dignity and choice also point to this possibility. ${ }^{39}$

\section{CONCLUSION}

The Scottish legislation is hugely significant in requiring nationwide state-funded support for menstruators. It is understandable that actors trying to challenge the inequality facing people who menstruate chose to focus on the tangible, relatively inexpensive and simple solution of free products. However, by placing objects, in this case menstrual products, into society, the law has implications for the meanings those objects convey and create, as well as for how we understand the law's relationship to

\footnotetext{
${ }^{37} I d$. at $\S 1(3)(\mathrm{b})$.

${ }^{38} I d$. at $\S 6 \mathrm{D}$.

${ }^{39}$ Period Products (Free Provision) (Scotland) Act 2021, § 6A (Scot.).
} 
injustice. Products can shift understandings of discrimination, disadvantage, and stigma, but they can also reinforce ideas of market-based and human-centered solutions that fail to unsettle structural causes of injustice. Critical attention to disposable menstrual products through an object-focused approach provides nuanced insights into how law operates and is legitimated through the material world and how it shapes individuals' menstrual worlds. Such object-informed analysis deepens our understanding of law's role in defining and responding to diverse menstrual experiences and illuminates the importance of critical analysis of menstrual items in the ongoing project of menstrual justice. 